\title{
URBAN CONSERVATION IN INTERNATIONAL CHARTERS: FROM THE ATHENS CHARTER TO THE HISTORIC URBAN LANDSCAPE RECOMMENDATION
}

\section{FRENDA Antonino ${ }^{1}$ VALLE Marco ${ }^{2}$}

\author{
${ }^{1}$ Antonino FRENDA; LINKS Foundation - leading innovation and knowledge for society, Turin \\ https://orcid.org/0000-0003-3102-1624 \\ ${ }^{2}$ Marco VALLE; LINKS Foundation - leading innovation and knowledge for society, Turin
}

ABSTRACT: The Interreg CE project "RUINS. Sustainable re-use, preservation and modern management of historical ruins in Central Europe - elaboration of integrated model and guidelines based on the synthesis of the best European experiences" implemented cultural development strategies through exchange of knowledge developed within a local and regional context that could be applied at a wider European level. The project applied an empowering bottom-up approach, in which local and regional stakeholders were actively engaged throughout the project's running time.

Cooperation of 6 countries with various traditions and experiences resulted in the development of universal models that could be applied for management, use and protection of medieval ruins all over Europe, providing a European added value.

The comprehensive management plans elaborated, help owners and managers of historical ruins to exploit the economic potential of this heritage in the economic development of regions and to preserve the value of medieval ruins as cultural heritage.

Due to its transnational character, the project has contributed to creation of the common European identity, strengthening of cooperation between international, national and local stakeholders both vertically and horizontally as well as promotion of exchanges between boundaries.

The paper aims to present the results and the experience gained during the RUINS projectimplementation by the LINKS Foundation (project partner), focusing on the inclusive and shared approaches carried out.

A summary of goals and recommendations achieved within the discussion panels/seminars arranged by the LINKS Foundation as well as the objectives and structure of the Output O.T2.1 "BEST PRACTICES HANDBOOK - Transnational model form of socially useful use of medieval ruins" will be provided.

KEY WORDS: Ruins; Inclusion; Participation; Management; Cooperation 


\section{Introduction}

Cultural heritage has a universal value for us as individuals, communities and societies; it shapes our identities and everyday lives and, for these reasons, it is important to be preserved and passed on to future generations.

The Ruins Project implemented strategies of cultural development through exchange of knowledge developed within a local and regional context that could be applied at a wider European level.

The traditional approach to preservation of ruins, in the past, was focused only on how to maintain historical ruins from a technical point of view.

The innovation of the project was to go beyond technical problems and to create an integrated model that brings together three elements: contemporary use, modern management and sustainable preservation of ruins.

Cooperation of 6 countries with various traditions and experiences resulted in the development of a universal models that could be applied for management, use and protection of medieval ruins all over Europe.

The neighbourhood and European perspective also enabled a broader and more intensive discussion of the quality standards for preserving and developing of cultural heritage: commitment to developing and preserving of cultural heritage does not end at national or European borders.

The project objective was to give "the second life" to medieval ruins through modern management and attributing of contemporary, socially useful functions, while preserving historical value of these sites.

In their evocative and fascinating image, ruins must be returned to the contemporary life from which they often appear, instead, dramatically separated.

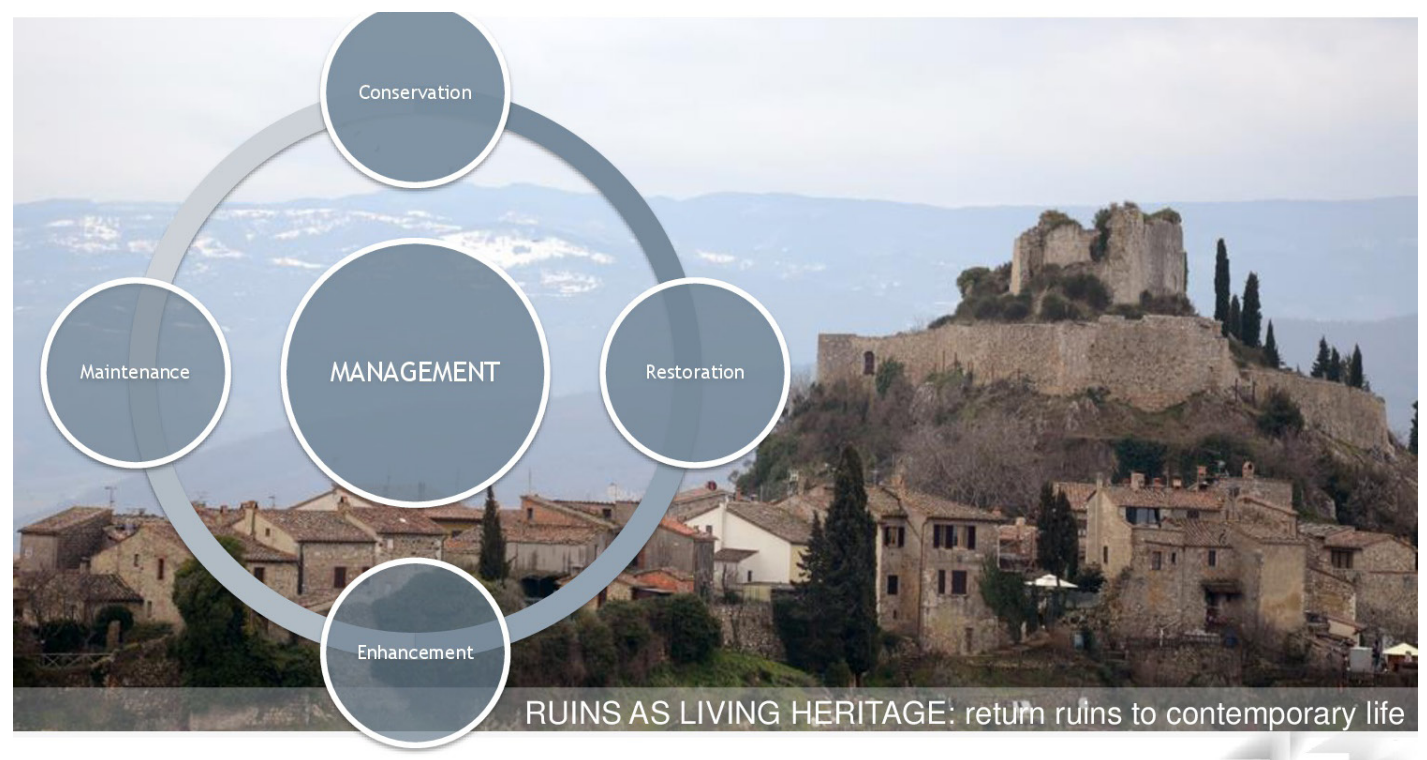




\section{Communities and Cultural Heritage}

While ruins are representative of European values and illustrative of European history and heritage, our aim should be to raise awareness of this heritage in order to create a stronger identification with Europe as well as further integration. In Europe, there are at least several thousand historical ruins. Owners and managers of these sites struggle with the same problems: protection of ruins is problematic due to ongoing process of destruction and modern use of ruins is limited.

The heritage identification and protection process cannot succeed without a certain level of heritage awareness and acceptance among visitors and community residents.

Our action in the field of cultural heritage should target the promotion of diversity and dialogue through access to heritage in order to foster a sense of identity, collective memory and mutual understanding within and between communities.

Citizen participation ${ }^{2}$ has become an ethical obligation and a political necessity. It revitalises society, strengthens democracy and creates governance that can renew the conditions of 'living together', encouraging well-being and a better quality of life.

In our future, the conservation of the world's natural and cultural heritage should be done wherever possible - with the active engagement of communities, which have a close relationship with the heritage in question.

Through cherishing of our cultural heritage, we can discover our diversity and start an intercultural conversation about what we have in common, reinforcing a sense of belonging to a common European space.

Cultural heritage is essential when the quality of a place is measured as it determines its attractiveness and thereby competitiveness for business, investors as well as creative and enterprising individuals.

Nowadays, we must combine the conservation goals with the objective of a smart, inclusive and sustainable growth.

Local communities must be encouraged to use their local cultural assets as a springboard for a process whereby local actors are encouraged to assume an active stewardship of the heritage and are empowered to develop that heritage in a responsible, profitable and sustainable manner.

\section{RUINS. Our heritage: where the past meets the future}

Inclusive and shared approaches have characterised the way of implementing methodologies and tools within the Interreg CE RUINS project.

Participation is a necessary ingredient of the sustainable development of ruins and the only way to ensure that a decision-making process achieves the project's goals.

${ }^{2}$ Cfr. Frenda A., Soldano S., Borlizzi P., Citizen participation \& cultural heritage» in Prooceedings of XI CONGRESO INTERNACIONAL AR\&PA 2018, El papel del patrimonio cultural en la construcción de la europa de los ciudadanos, 8- 10 de noviembre 2018, Valladolid, pp. 237-243; 
Within the project, inclusion and exchanges among stakeholders were ensured by a sequence of discussion panels and seminars that became the occasion to share remarks and experiences with and among wide national and international public. The coexistence of scholars, professors, people responsible for the protection, UNESCO site managers and experts involved in the use and management of cultural heritage made it possible to explain the points of view of the various stakeholders who, in various capacities, may be involved in the management and use of a ruined site $^{3}$.

Participants had the opportunity to deepen their knowledge of the most current approaches to conservation, sustainable use and management of ruins, which represent, throughout Europe, the heritage of inestimable historical and cultural value, yet extremely fragile one, which the professional must know how to deal with correctly so as not to jeopardise its authenticity.

The first event "Medieval ruins between reuse and enhancement. Comparing experiences. National discussion panel with stakeholders on sustainable use and reuse of ruined sites"4 was dedicated to the themes of sustainable use and reuse of medieval ruins, with the aim to find the balance between the needs of stakeholders and public expectations concerning the use of medieval ruins and preservation of authenticity and historical value of medieval ruins (as historical monuments).

The national discussion panel dealt with the themes of conservation, re-functionalization and management of historical buildings, with a specific focus on medieval ruins. Theoretical and practical models were provided as regards the themes of architectural and archaeological restoration, projects of contemporary reuse, management of cultural heritage, with an extensive presentation of case studies referring to both the national and international context.

The main purposes of the panel were:

- to stimulate a debate among different kinds of professionals and stakeholders on the possibilities of a sustainable and contemporary use and reuse of historical ruined sites;

- to identify shared approaches and methodologies in restoration and reuse projects of historical ruined sites;

- to share case studies and significant design solutions for the development of subsequent steps of the RUINS project.

In the last half century, the European debate on the theme of the enhancement of cultural heritage has changed the point of view from which assets are perceived: no longer a legacy to be guarded and contemplated, but a dynamic reality with an active role in the contemporary world.

\footnotetext{
${ }^{3}$ As regards the audience, most of them were architects, representatives of the Association of Architects of Turin (OAT), which recognized the scientific value of the panel promoting the event in its own website and acknowledging the event as a professional training event for architects. Further participants included (in order of presence) scholars, researchers, students and citizens.

4 The event, organised and hosted by LINKS Foundation in Turin (Italy) was held on 19th October 2018 and registered 71 participants ( 16 speakers and 55 listeners).
} 
The new approach to the heritage of the past has involved, in addition to the restoration and architectural project, also the artistic creations, determining different balances in the relationship between the new and the old. The monument, previously viewed as predetermined and nonmodifiable reality, is now perceived as a malleable and varied material to dialogue with.

The first evidence deriving from this reflection is that, for the protection and conservation of a medieval ruin, as well as any historical artefact, it is necessary to overcome the concept of the mere physical protection of the object to open up to a deep relationship with the past to put it in a relationship with the present.

One of the main issues raised during the panel is that the reuse project should be an integral part of the overall conservation activity. The utility of ruined sites must be considered before starting any restoration or enhancement works. If not, the risk is that the reuse project is useless for community and probably not sustainable.

Another important issue is linked to the correct approach to the historical remains and its relationship with the addition of new contemporary parts. The frequent lack of deep analysis and studies on the consistency, materials, state of conservation of the ruin poses a risk for its correct interpretation and for the subsequent choice of a compatible use.

New design projects have to consider the values of the sites and create a dialogue with the ancient remains respecting the principles of authenticity, compatibility, reversibility, recognizability and minimum intervention.

Not all ruined sites are monumental, but most of them are an example of minor architecture and a professional should manage this aspect in a proper way.

Ruined sites are strongly linked to their socio-cultural context and represent the identity and the memory of a place. Recognizing the value and importance of ruined sites help us to think about a socially sustainable reuse that must be the guide of any restoration work on ruins.

The goal to be pursued necessarily must be that of attributing a correct meaning to the ruin, pursuant to the logic of conservation and with respect of the monument to be enhanced, through transformations compatible with the authenticity of the ruined work, avoiding any deformations and alterations of the visual and formal perception of the ruin.

Knowledge and communication of historical ruins are fundamental steps that help to reconnect them to the community.

Conservation approaches and choices must be part of the communication programme in order to improve the knowledge of the site and increase awareness of the community who is the final user of the ruined site. Investigating the perception of a ruined site by the community can guide restoration projects and reuse that must take into account the citizens' needs and expectations.

The second event "Ruins: Living Heritage. Protection - Use - Management"s followed the debate already started during the first panel, taking it to a subsequent and higher level, and aimed at best possible attuning of the developed comprehensive plans of preservation, management and use to the real needs and problems related to historical ruins.

${ }^{5}$ The event, organised and hosted by the LINKS Foundation in Turin (Italy) was held on 20 June 2019 and registered 56 participants (1 remotely), including 8 Expert Lecturers. 

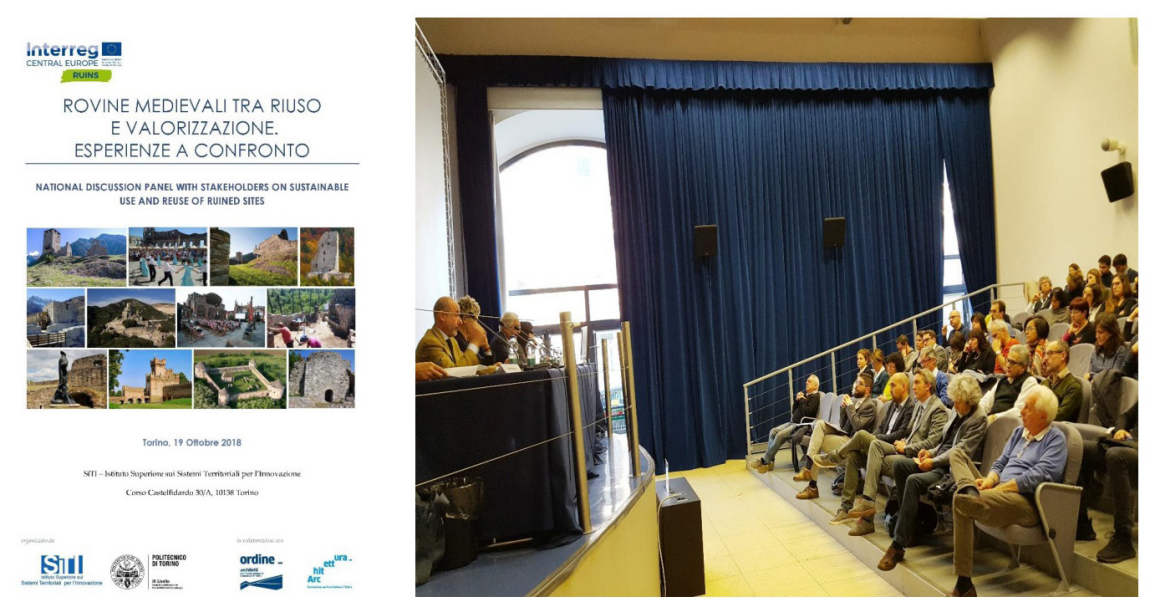

The national discussion panel with stakeholders dealt with the themes of protection, use and management of medieval ruins with a particular focus on heritage included within UNESCO sites. A new point of view on the topic was to tell how UNESCO site managers deal with the theme of conservation, management and use of historical ruins.

Theoretical and practical models were provided on the themes of architectural and archaeological protection, projects of reuse, management of cultural heritage, with an extensive presentation of case studies referring to the national context.

Characteristics of the issues raised during the panel constituted food for thought for the implementation of transnational guidelines for development of comprehensive management plans for medieval ruins.

The basic assumption is that protection, use and management of ruined sites must always be carried out by experts, especially in the case of sites with the presence of Outstanding Universal Values (such us UNESCO ones).

Knowledge is the core of protection. Only a well-studied ruined site can be opportunely protected and managed. A lack of functionality of medieval ruins leaves limited opportunities for establishing of a viable economic future of these sites.

Reuse is surely one of the best ways to ensure the preservation of an antique object: a functionfree monument deteriorates rapidly, while one that is kept efficient remains alive. Case studies provided a varied and consistent overview for the implementation of the project.

The conclusion that emerged is that ruins constitute an area of interest for experiments and theoretical digressions in the field of cultural heritage protection, use and management.

The term "ruin" has the double meaning of indicating both a process and the outcome of that process. It indicates the physical destruction or disintegration of something or the state of disintegrating or being destroyed as well. Ruins, therefore, not only represent the tangible part of the past that partly disappeared but are, above all, a generator of memory and can represent an opportunity to retrace history in order to rediscover identity. In their evocative and fascinating image, ruins must be returned to the contemporary life from which they often appear, instead, dramatically separated. 

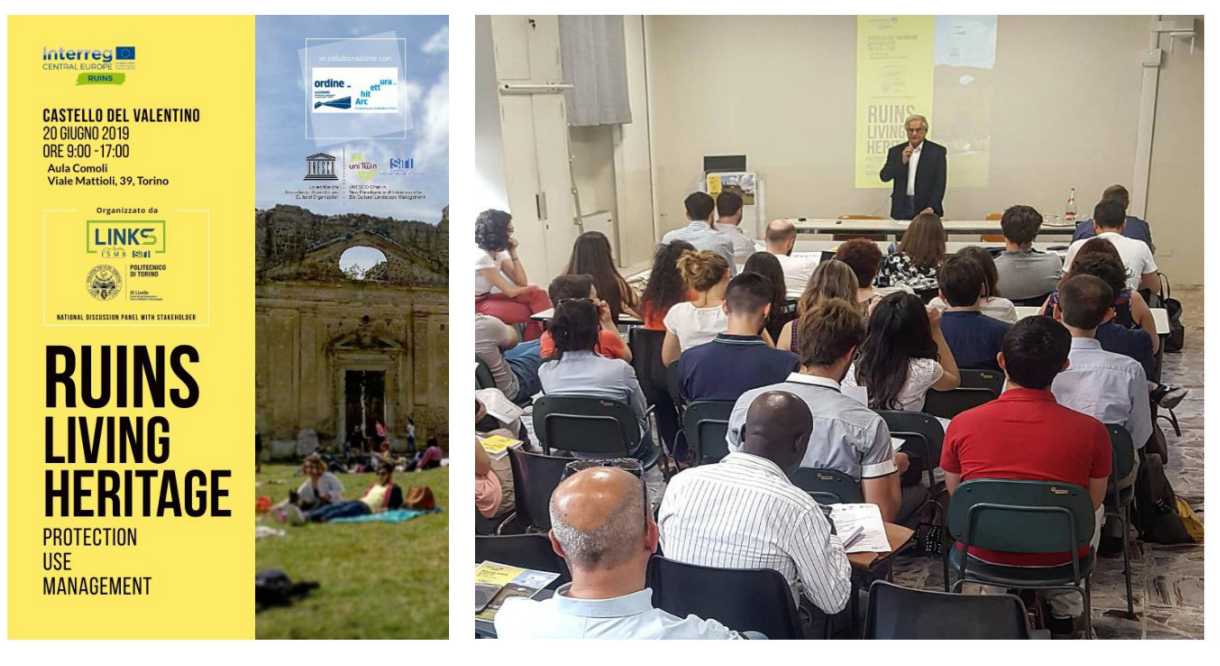

The sequence of events was concluded with the webinar "What future for the management of cultural heritage? Dialogue around an effective post-pandemic protection and enhancement" that dealt with the theme of the management of cultural sites with a focus on the heritage included in the UNESCO World Heritage List. To respond effectively to the World Heritage Convention (1972), in 2002 the World Heritage Centre established that the inclusion of new sites in the List must be conditional on the drafting of Management Plans. In 2004, it recommended the Management Plan also for the sites already included in the List, thus providing the local authorities with a valid tool for making the heritage known and for defending and monitoring it. Being aware that the Management Plan represents a useful tool for conservation, protection and for the enhancement of the entire cultural heritage as a whole, the webinar aimed to consider the necessity to readapt the way of thinking on the models of cultural heritage management in support of the exit from the current period of a global crisis.

Theoretical and practical models were provided on the theme of management of cultural heritage, with an extensive presentation of case studies referring to the national and international context.

In the ever-changing scenario, the main challenge is related to maintenance of the equilibrium between conservation and transformation, according to a strategic vision of development, more connected to the socio-cultural dynamics of the territories that are context dependent.

The webinar raised a general interest in new management approaches, which demand more dynamicity, proactivity and bounce-forward perspectives. Flexibility is recognized as the leading tool to overcome pandemic and other wicked problems, both in operational field and in the theoretical sector. New management plans need to be more inclusive and people-centred, seeking the human well-being as an important goal. Digital instruments will support the dissemination of cultural heritage to a larger audience to counteract the limitations superimposed by the pandemic restrictions.

${ }^{6}$ The webinar, organised by the LINKS Foundation, registered 165 participants (including 7 expert speakers) and substituted a previously planned seminar "Management for an effective protection and enhancement of cultural heritage. Comparing Experiences" cancelled due to the COVID-19 emergency. 
Among the audience, there is a growing awareness of the importance of the contribution of resilience and dynamic tools in the management of the cultural heritage. Digital conferences or symposia allow a greater number of people to be involved than physical ones and should be proposed more often in the future to increase the number of community members involved.
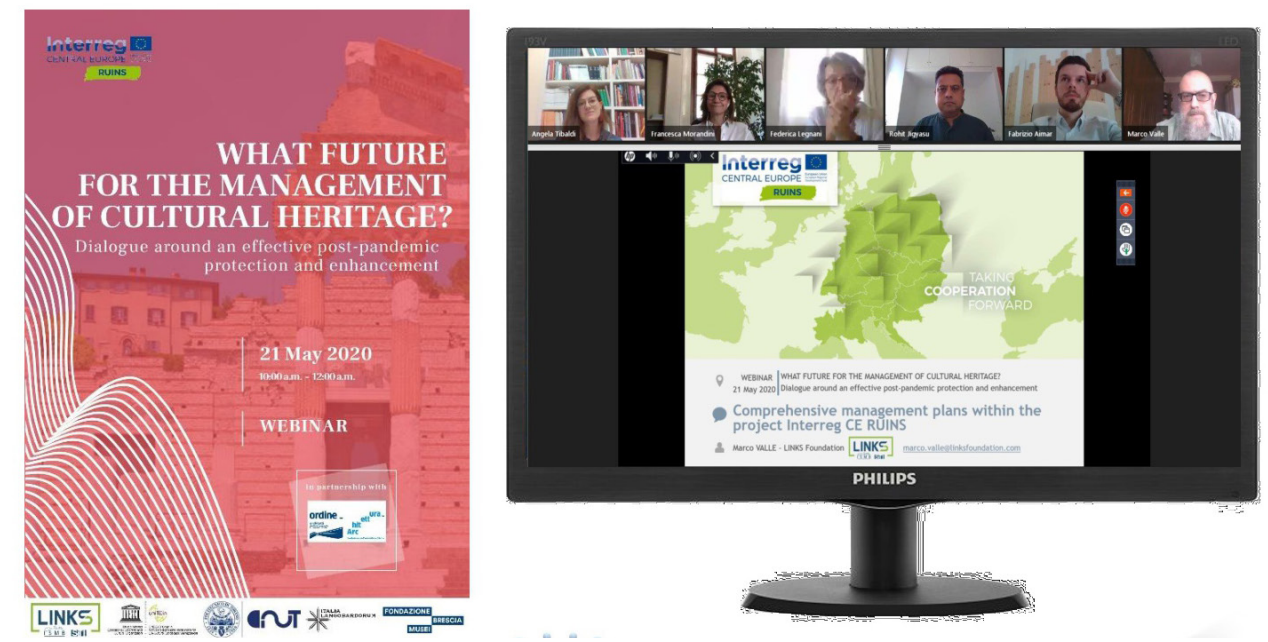

The seminars constituted a fundamental and indispensable phase of knowledge, useful for the development of transnational models of the contemporary use of medieval ruins.

They also enabled exchanges that were very important and useful in developing of the "BEST PRACTICES HANDBOOK - Transnational model form of socially useful use of medieval ruins".

The handbook aims to supply an operational tool useful for guiding of the owners and managers of the thousands of medieval ruins around Europe towards sustainable re-use, preservation and modern management of historical ruins.

The handbook contains practical examples of intervention and several case studies at international level. It summarises and describes the tools and methods for the development of the individual phases of the elaboration of a project of reuse of historical ruined sites.

Important theoretical references are the most consolidated theories of restoration and use of historical heritage at the international level with a strong background linked to the Italian restoration school, which has long debated the theme of the reuse of historic buildings.

7 The handbook contains an outline composed of 5 chapters that try to respond in an exhaustive way to the aims related to the contemporary use of historical ruins. It is closely interconnected and coordinated with the other two handbooks implemented within the Interreg Central Europe Ruins project: one related to the issue of preservation, the other to contemporary management. 


\section{Interreg CENTRAL EUROPE :
RUINS \\ TRANSNATIONAL MODEL FORM \\ OF SOCIALLY USEFUL USE \\ OF HISTORIC RUINS}

Best practices handbook

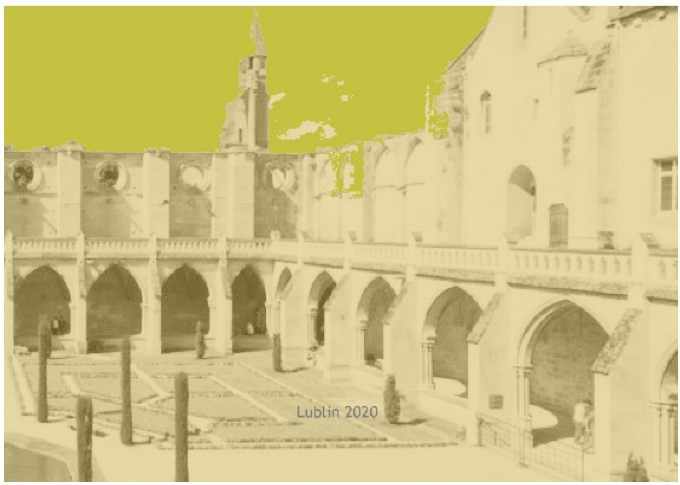

\section{Conclusions}

The RUINS project had a big role to play in building of the future of Europe, making use of the increasing worldwide demand for touristic offers relating to the ruins.

What is more, the project highlighted and boosted the important role of cultural heritage in Europe as a resource and a common good. The project partners undertook several coordinated actions, at the same time acting as an open-air laboratory of European construction.

The project fully promoted European values, heritage-related skills, common history, intercultural dialogue and social inclusion through education, non-formal and lifelong learning.

Preservation, education and use embedded within the framework of cultural tourism can be better organized as a cross border endeavour.

The RUINS project aimed to raise awareness of these connections in order to create a stronger identification with Europe and, as a prerequisite for further European integration, to achieve a closer connection, network and collaboration between and with the stakeholders' policy makers.

\section{Author Contributions}

This paper is the result of exchanges between the authors. 


\section{Antonino Frenda}

\section{Bibliography}

AAS C., Ladkin A., Fletcher J., Stakeholder collaboration and heritage management. Annals of Tourism Research, 32(1), 2005, pp. 28-48.

Ashurst J., Conservation of Ruins. Amsterdam; London: Elsevier/Butterworth-Heinemann, 2007. Barbanera M., Relitti riletti: metamorfosi delle rovine e identità culturale, Torino: Bollati Boringhieri, 2009.

de Camargo P., Using tourist resources as tools for teaching and creating awareness of heritage in a local community, [in:] G. Richards (ed.) Cultural Tourism: Global and Local Perspectives, New York: Haworth, 2007, pp. 239-256.

Frenda A., Soldano S., Borlizzi P., Citizen participation \& cultural heritage» in Proceedings of XI CONGRESO INTERNACIONAL ARઐPA 2018, El papel del patrimonio cultural en la construcción de la Europa de los ciudadanos, 8- 10 de noviembre 2018, Valladolid, 2018, pp. 237-243.

Marc A., Serageldin I., Taboroff J., Community Participation in the Conservation of Cultural Heritage. Washington, DC: World Bank, 1994.

Montella M., Valore e valorizzazione del patrimonio culturale storico, Milano: Mondadori Electa, 2009.

Oteri A. M., Rovine. Visioni, teorie, restauri del rudere in architettura, Argos, 2009.

Tortora G., Semantica delle rovine, Roma: Manifestolibri, 2006. 